\title{
CHANGES IN SALIVARY HORMONES CONCENTRATION DURING THE PREPARATION AND COMPETITION PERIOD IN OLYMPIC WEIGHTLIFTERS
}

\author{
Milan Kováč ml. ${ }^{1}$, Eugen Laczo ${ }^{1}$, Matej Vajda ${ }^{2}$, Iveta Cihová ${ }^{1}$, Jaroslava Babková ${ }^{3}$
}

\author{
${ }^{1}$ Department of Track and Field, Faculty of Physical Education and Sports, Comenius University \\ in Bratislava, Slovakia \\ ${ }^{2}$ Department of Sport Kinanthropology, Faculty of Physical Education and Sports, Comenius University \\ in Bratislava, Slovakia \\ ${ }^{3}$ Department of Physiology, Faculty of Medicine, Comenius University in Bratislava, Slovakia
}

\begin{abstract}
Summary: Endogenous hormones are essential for physiological reactions and influence the adaptation to weightlifting training by modulating anabolic and catabolic processes. It seems that testosterone and cortisol are playing a key role in anabolic and catabolic processes in resistance training. Eight elite Czech and Slovak weightlifters volunteered in present study. The testosterone and cortisol were measured in 4 testing sessions over 18 weeks during preparation and competition period. The training protocol consisted of three specific weightlifting exercises. The saliva samples were collected in 4 testing sessions, pre and $5 \mathrm{~min}, 15 \mathrm{~min}$ and $30 \mathrm{~min}$ after protocol, respectively. The basal level of salivary testosterone and cortisol remains unchanged during preparation and competition period. Also, acute testosterone response was not observed over the monitored period. However, acute decrease of cortisol were found between pre intervention and post $5(\mathrm{p} \leq 0.01), 15(\mathrm{p} \leq 0.01)$, and $30 \min (\mathrm{p} \leq 0.05)$ during preparation periods. While in competition period was found significant decrease $(p \leq 0.05)$ only $5 \mathrm{~min}$ after testing protocol. The testosterone/cortisol ratio significantly increased during preparation periods $(\mathrm{p} \leq 0.01)$, but not in competition period. Results indicated that the routine assessment of testosterone and cortisol may provide an effective way to monitor acute and chronic adaptive response to weightlifting training. Our results suggest that cortisol, not the testosterone is an important component of adaptation during elite weightlifting training.
\end{abstract}

Key words: weightlifting, testosterone, cortisol, testosterone/cortisol ratio, saliva

DOI 10.1515/afepuc-2017-0002

(C) Acta Facultatis Educationis Physicae Universitatis Comenianae 


\section{Introduction}

The testosterone ( $\mathrm{T}$ ) as an androgen anabolic steroid which likely plays a key role in adaptation to training program has largely been attributed to a morphological mechanisms involving protein metabolism, resulting in strength gain (Tremblay et al. 2004) and also muscle and bone growth (Hoffman 2014). On the other hand, cortisol (C) is one of the most important stress hormones, the glucocorticoid class, mediating training adaptations, by decreasing protein synthesis and increasing protein breakdown (Viru \& Viru 2004). Kraemer et al. (2004) suggest that monitoring of concentration of testosterone and cortisol can be used as parameter reflecting an athlete's response to training and competition. Relationship between testosterone and cortisol level ( $\mathrm{T} / \mathrm{C}$ ratio) has been associated with anabolic/catabolic status of athlete's organism (Grandys et al. 2016). Also, the T/C ratio can be potential marker for determination of overtraining and recovery status of athletes (Hug et al. 2003).

Previous investigations found the influence of strength training program on testosterone and cortisol level in strength-trained subjects (Gotshalk et al. 1997; Kramer et al. 1997; Tremblay et al. 2004; Spiering et al. 2008). Hakkinen et al. (1988) suggest that hormonal responses of weightlifters to strength training program are similar to the strengthtrained athletes. In addition, Storey \& Smith (2012) proposed that the regular evaluation of basal testosterone, cortisol and $\mathrm{T} / \mathrm{C}$ ratio can provide an effective way for establishing the acute and chronic adaptive response to weightlifting training.

Currently, the salivary analyses of biomarkers are widely used in medicine and sports science. The salivary analyses presented non-invasive, stress-free, sampling procedure, which can be used for determination of hormones in situations where blood sampling is difficult to perform (Aardal \& Hom 1995). The relationship between salivary and serum levels of biomarkers is shown to be very high (Wining et al. 1983; Luisi et al. 1984; Kirchbaum et al. 1989; Lac et al. 1993; Morgan 2009). In addition, for steroid hormones, the concentrations found in saliva are representative of the total serum and serum free concentrations (Vining et al. 1983, Johnson et al. 1987, Lac et al. 1993). Johnoson et al. (1987) and Wang et al. (1981) found high correlation between salivary testosterone and serum total $\mathrm{T}$ and serum free $\mathrm{T}$ at the rest. Morgan et al. (2009) suggest that salivary measurements of testosterone, cortisol and T/C ratio can be used as a reference for their respective blood concentrations in resting conditions.

The purpose of this study was to examine changes of salivary testosterone and cortisol level during preparation and competitive period of elite weightlifters. We hypothesized, that 
different basal level and acute responses of selected hormones will be observed over the preparation and competition period in weightlifting.

\section{Methods}

\section{Subjects}

Eight elite weightlifters (Czech Republic - 4 and Slovak - 4 National Team members) volunteered in present study. General characteristics of participants, age $26.56 \pm$ 3.43 years, weight $94.76 \pm 17.60 \mathrm{~kg}$ at the start of this study, average height of participants was $177.00 \pm 7.05 \mathrm{~cm}$. All participants had more than 8 years weightlifting training experience. The inclusion criteria for this study were sport performance expressed by Sinclair points scale (for evaluation criteria of sport performance without difference in bodyweight). Participants had to have more than 350 Sinclair points.

\section{Experimental design}

All of the subjects went through four testing sessions over the 18-weeks of preparation and competition periods were monitored (Figure 1).

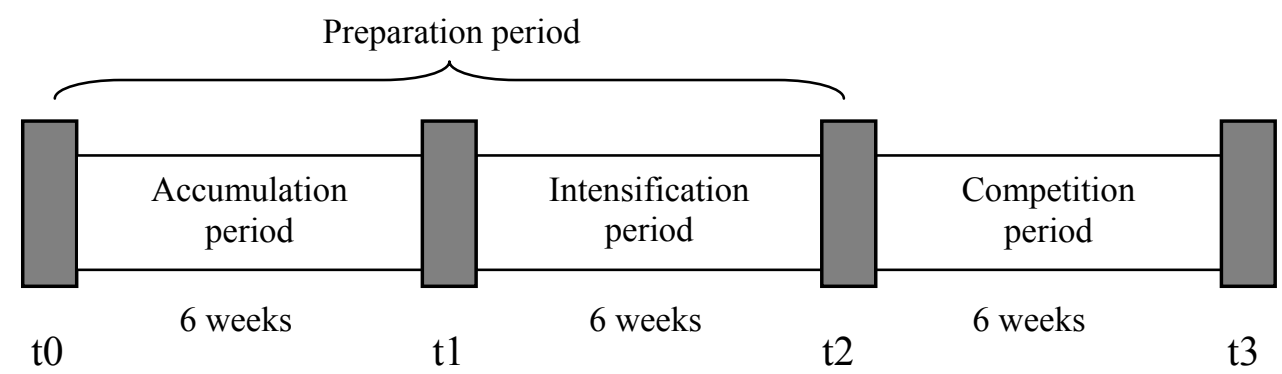

Figure 1

Testing sessions over monitoring period, t0 - entry testing session, $t 1$ - testing session after accumulation period, $t 2$ - testing session after intensification period, $t 3$ - testing session after competition period

Testing sessions consisted of training protocol with three specific weightlifting exercises. All of exercises were performed with maximal effort. A linear position transducer attached to the right side of the bar (Tendo weightlifting analyser; Tendosport, Trenčín, Slovakia) was used to control of maximal effort. Standardised general and special warm-up protocol was used before each testing session. First exercise was muscle snatch - start at $50 \%$ 1RM with graduation to $1 \mathrm{RM}$ (6 sets with 1 repetition at weight). Second exercise was high pull with snatch grip - start at $90 \%$ with graduation to 1RM (6 sets with 1 repetition at weight). Last exercise was front squat - start at $60 \% 1 \mathrm{RM}$ and ending two weights above average power maximum ( 7 sets with 1 repetition at weight). The training protocol was based 
on our previous investigation (Laczo et al. 2012). Rest interval was 2 - 3 min between the sets and exercises, respectively.

Saliva samples $(\sim 1 \mathrm{~mL})$ were collected by passive drool before and after 5,15 , and 30 min training protocol, respectively. To avoid any confounding effects due to variations in circadian rhythm all testing sessions were performed at the same time of day. All testing sessions were completed in same time between 9:00 and 11:00 hours, with participants being awake for more than 90 min to account for an early morning rise in hormones, and without food and drink 60 min before sampling. During the each testing sessions consumption of one litre of pure water was allowed.

\section{Salivary hormone assessment}

The salivette with a plain cotton swab were used (Sarstedt, Nurmbrecht, Germany). All samples were stored and subsequently refrigerated at $-60^{\circ} \mathrm{C}$ for future analysis. The samples were analysed at Department of Physiology, Faculty of Medicine, Comenius University in Bratislava. The salivary testosterone (pmol/L) and cortisol (nmol/L) concentrations were determined using commercially available ELISA kits (Salimetrics, State College, PA, USA). Centrifugation for $2 \mathrm{~min}$ at $1000 \mathrm{~g}$, without repeated thawing and refreezing, were preceded according to the recommendations (Salimetrics, State College, PA, USA).

\section{Statistical analyses}

Standard descriptive statistics were calculated for all measured parameters. Because of the low sample size, nonparametric statistics were used. The Wilcoxon T-test and Friedman test were used for statistical analyses. The criterion for significance was set at $p \leq 0.05(*)$ and $\mathrm{p} \leq 0.01(* *)$. Statistical analyses were completed in SPSS 20.

\section{Results}

In our study were investigated acute and basal changes of concentration of testosterone, cortisol and $\mathrm{T} / \mathrm{C}$ ratio during accumulation, intensification and competition period.

Significant decrease of acute cortisol response was observed between Pre to Post 5 and Pre to Post $15 \min (\mathrm{p} \leq 0.01)$ before accumulation period. Following accumulation period, significant decreases were registered between Pre to Post 5, Post $15(\mathrm{p} \leq 0.01)$ and Post 30 $\min (\mathrm{p} \leq 0.05)$, respectively. The same decreases were observed after intensification period 
between Pre to Post 5, Post $15(\mathrm{p} \leq 0.01)$ and Post $30 \mathrm{~min}(\mathrm{p} \leq 0.05)$, respectively. After competition period, significant decrease was found between Pre and Post 15 min only.

No significant differences were observed between monitored training periods in basal levels of monitored parameters. Also, in testosterone no significant changes were found in acute response to testing protocol in any times.
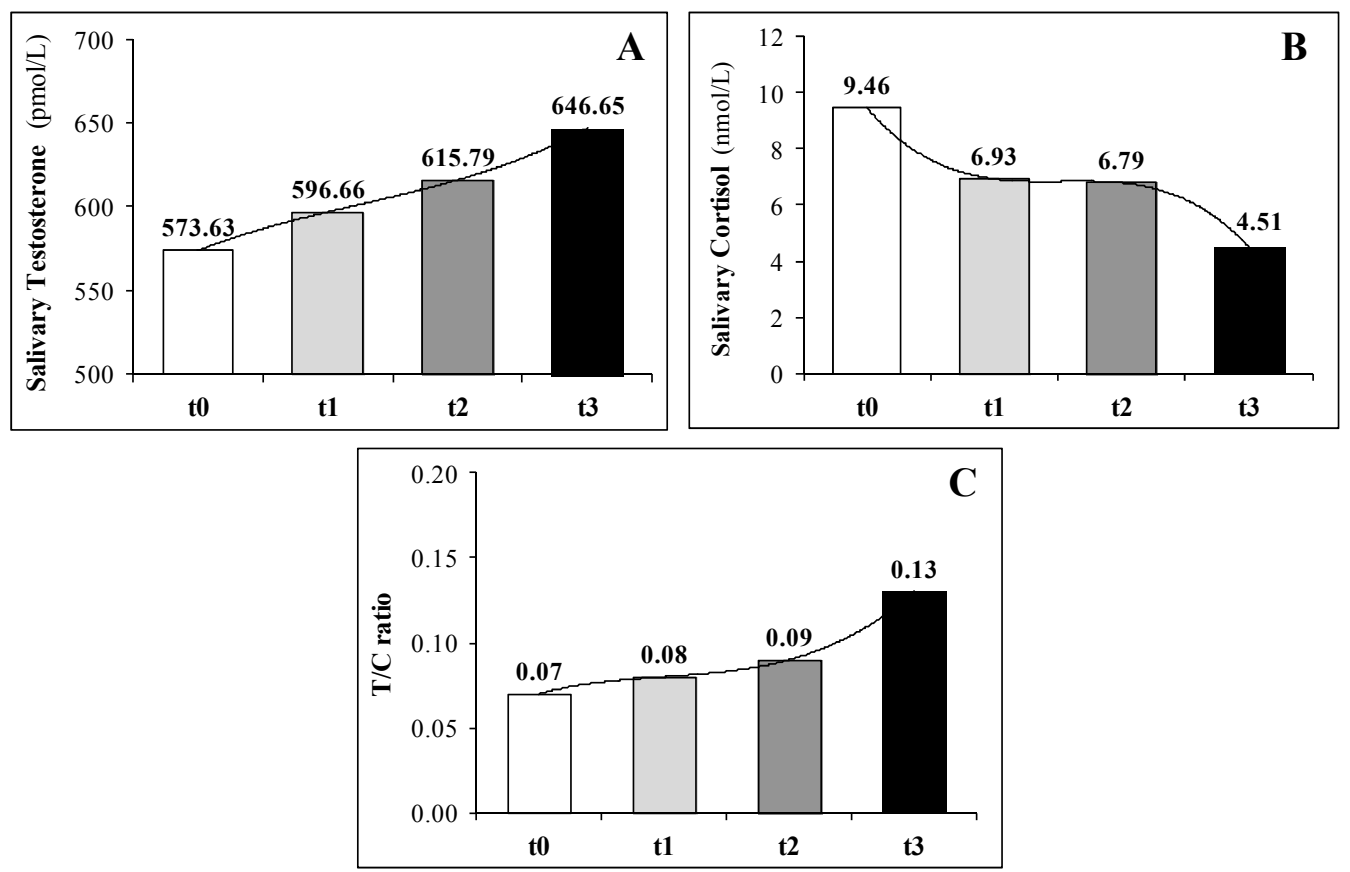

Figure 2

Changes of basal salivary testosterone concentrations (A), salivary cortisol (B) and T/C ratio (C) during preparation and competition period. to - entry testing session, $t 1$ - testing session after accumulation period, $t 2$ - testing session after intensification period, $t 3$ - testing session after competition period. Values are presented as median 

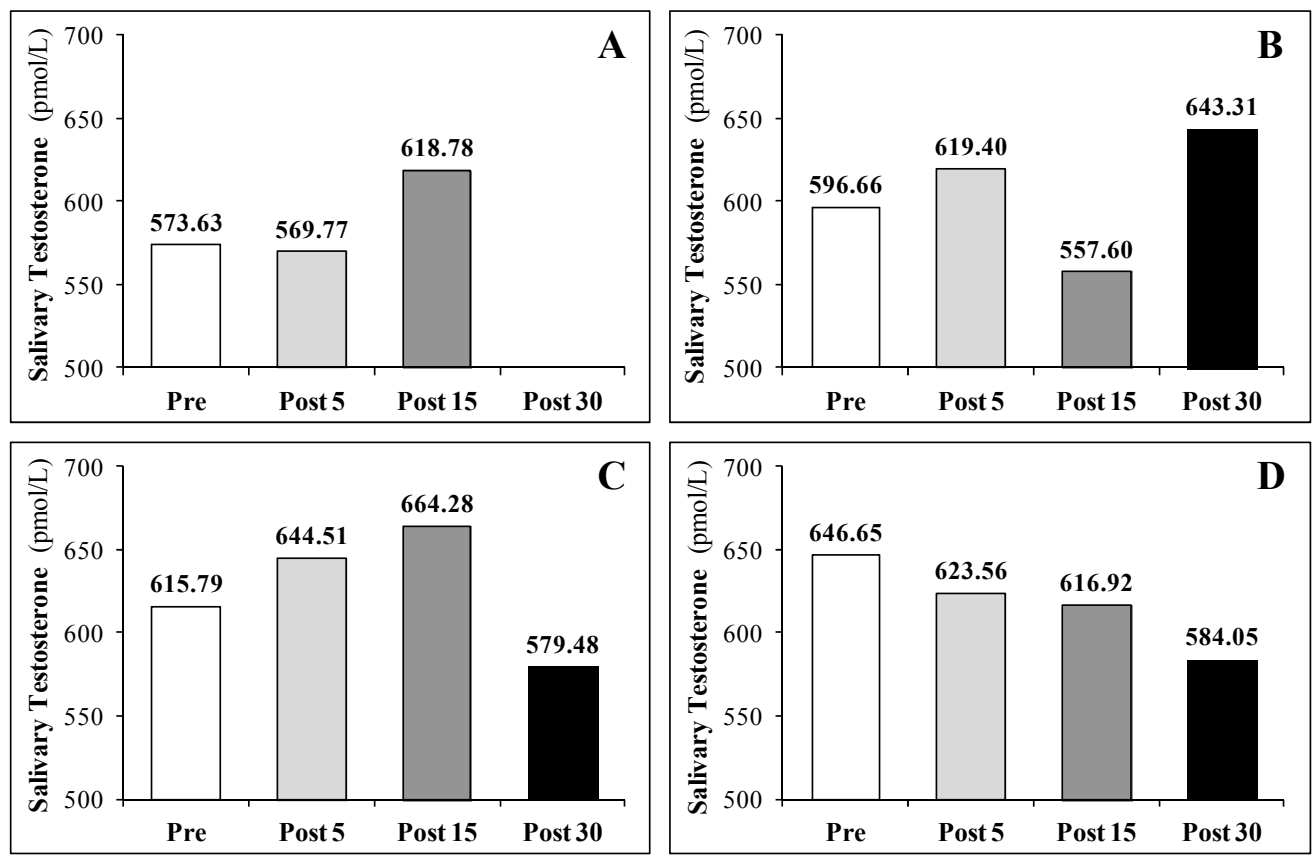

Figure 3

Changes in acute response of salivary testosterone before accumulation period (A), after accumulation period (B), after intensification period (C), competition period (D). Before (Pre), 5 min (Post 5), 15 min (Post 15) and 30 min (Post 30) after testing session. Values are presented as median
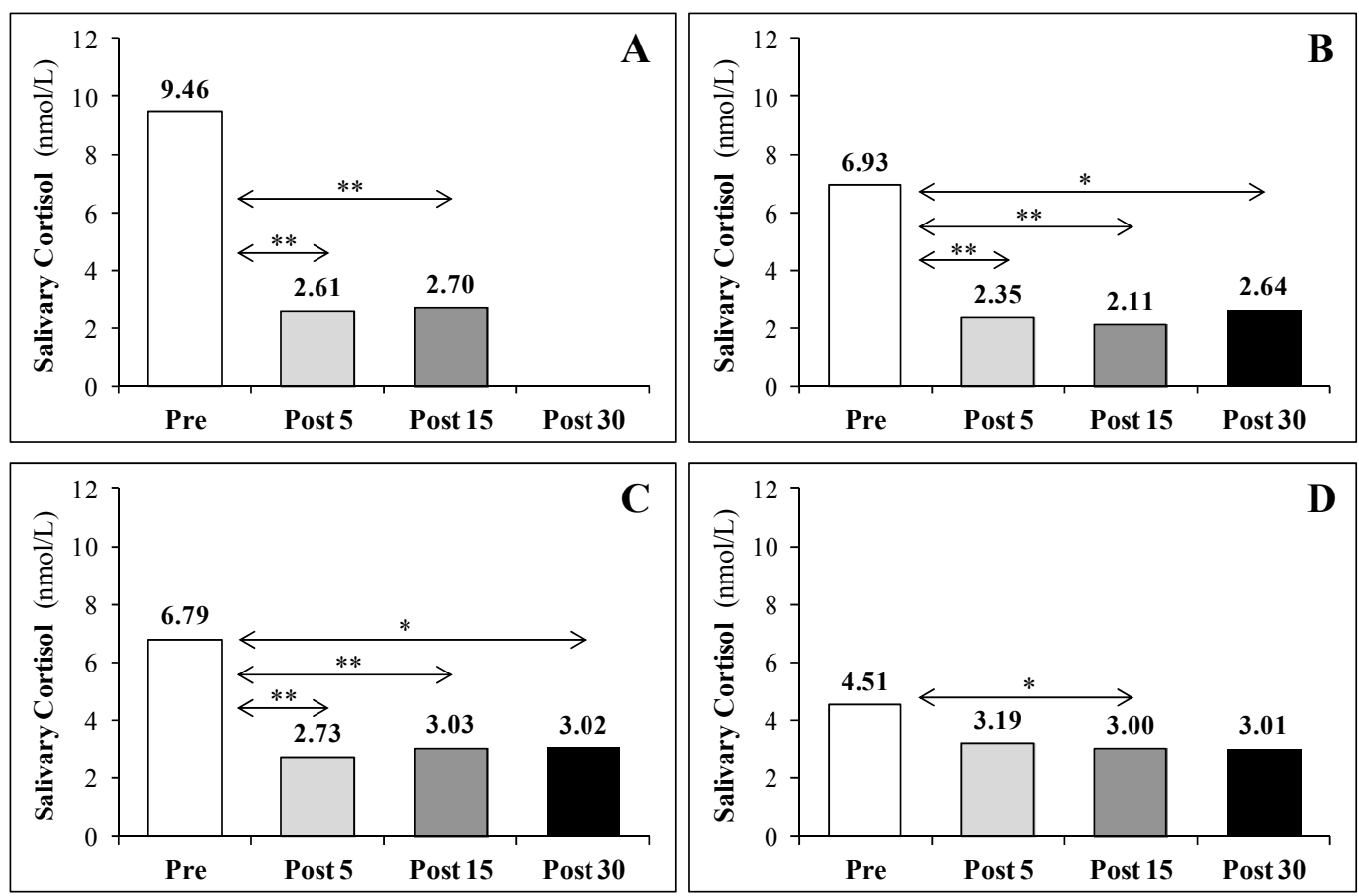

Figure 4

Changes in acute response of salivary cortisol before accumulation period (A), after accumulation period (B), after intensification period (C), after competition period (D). Before (Pre), 5 min (Post 5), 15 min (Post 15) and 30 min (Post 30) after testing session. Values are presented as median.

* Significant difference $p \leq 0.05$ and $* *$ Significant difference $p \leq 0.01$ 

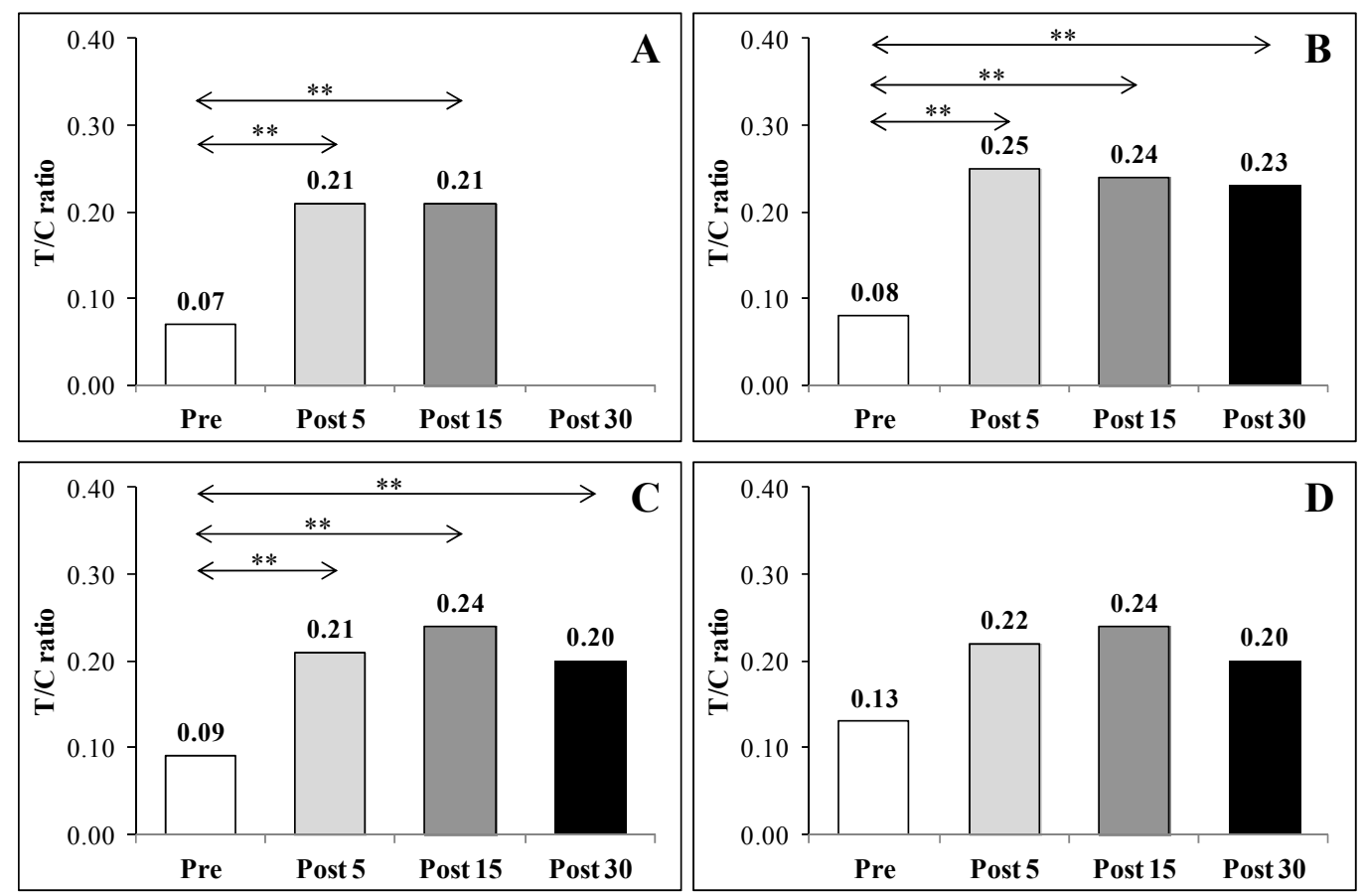

Figure 5

Changes in acute response of $T / C$ ratio before accumulation period $(A)$, after accumulation period (B), after intensification period (C), after competition period (D). Before (Pre), $5 \mathrm{~min}$ (Post 5), $15 \mathrm{~min}$ (Post 15) and $30 \mathrm{~min}$ (Post 30) after testing session. Values are presented as median. ${ }^{*}$ Significant difference $p \leq 0.05$ and $* *$ Significant difference $p \leq 0.01$

Last monitored parameter was the $\mathrm{T} / \mathrm{C}$ ratio. Before the accumulation period, significant increases of T/C ratio were observed between Pre to Post 5 and $15 \min (\mathrm{p} \leq 0.01)$, respectively. In the next two time periods, after accumulation and intensification period, significant increase were registered between Pre to Post 5, 15 and $30 \mathrm{~min}(\mathrm{p} \leq 0.01)$, respectively. After competition period, no significant changes were found. No significant differences were found in Post testing comparisons in each monitored parameters.

\section{Discussion}

The present study aimed to compare the endocrine response of elite weightlifters during preparation and competition period. The main findings of our study are that no significant differences were observed in basal concentration of salivary testosterone and cortisol between monitored periods. However, the results indicated opposite tendency in testosterone and cortisol basal concentrations during selected periods. While concentration of testosterone had progressive character from preparation to competition period, cortisol concentration has decreasing trend. 
The published data about effect of training intervention on changes of basal testosterone level remain controversial. In the present study, adaptive changes of basal testosterone level were not observed during monitored period. Our results are supported by previous research of Hakkinen et al. $(1985,1987)$ and Guilhem et al. (2015), who did not find significant changes of resting testosterone following weightlifting training program. In opposite, few studies reported increase of basal testosterone after training program in weightlifters (Hakkinen et al. 1988; Kraemer et al. 1992). The similar controversy, as for testosterone, has been found in changes of basal cortisol following training program (Hakkinen \& Pakkarinen 1991; Potteiger et al. 1995; Kraemer et al. 1998). Our results are in agreement with Guilhem et al. (2015) who did not observe significant changes in cortisol level during preparation and pre-competitive period.

The opposite trend led to increase of T/C ratio, which has been associated with anabolic/catabolic status (Grandys et al. 2016) and reflected principles of adaptation of athletes to resistance training. Hakkinen et al. (1987) reported that increase of T/C ratio positively related to weightlifting performance. Relationship between the training volume and $\mathrm{T} / \mathrm{C}$ ratio in weightlifters demonstrated Haff et al. (2008). Data indicated that $37 \%$ reduction of training volume led to significant increase basal $\mathrm{T} / \mathrm{C}$ ratios. These results had been in accordance with the present study. The T/C ratio systematically increased from preparation with high training volume to competition period with diminution of training volume. On the other hand, decrease of $\mathrm{T} / \mathrm{C}$ ration has been associated as an indicator of overtraining (Vervoorn et al. 1991; Kreher et al. 2012) and insufficient recovery (Passelerque \& Lac 1999). In addition, Storey \& Smith (2012) suggest that the routine assessment of the basal $\mathrm{T} / \mathrm{C}$ ration may provide and effective way in which to measure acute and chronic adaptive response to weightlifting training.

Acute hormonal response to resistance exercise has been depended on training characteristics such as number of exercises, load, volume and intensity (Kraemer \& Ratamess 2005; Crewther et al. 2006). In addition, level of athletic performance strongly affected acute hormonal response (Tremblay et. al. 2004; Crewther et al. 2006).

In testosterone, no significant changes were found in acute response to training protocol in any times. Our data demonstrated that training protocol has not been enough to induce acute testosterone changes in monitored period. On the other side, acute decrease of cortisol was found following each monitored period but an acute response was gradually reduced over the monitored period. In contrary, Hakkinen \& Pakarinen (1993) shown, that weightlifting training session did not induce acute changes of cortisol concentrations. 


\section{Conclusions}

In summary, our results showed no changes in basal concentration of salivary testosterone and cortisol over the accumulation, intensification and competition periods in Olympic weightlifters. Acute decrease of cortisol concentration was found following each monitored period and the response was gradually reduced over the monitored period. Changes in acute response of $\mathrm{T} / \mathrm{C}$ ratio over accumulation and intensification periods were caused by acute decrease of cortisol and no changes in acute response of testosterone.

The current trends in elite sport training are preferring the systematic approach to the monitoring of adaptation processes. Knowledge about adaptation responses across different physiological systems and levels represent significant instrument for performance improvements. Monitoring of acute and chronic hormonal response to the resistance training may be useful for effective training personalization of elite weightlifters.

\section{Aknowledgements}

We are grateful to all coaches and participants from the Czech and Slovak national weightlifting team. This investigation was financed from grants UK/200/2016, UK/435/2015 and VEGA 1/0232/14.

\section{References}

1. AARDAL, E. \& A. HOM, 1995. Cortisol in Saliva - Reference Ranges and Relation to Cortisol in Serum. In: Eur J Clin Chem Clin Biochem 33:927-932.

2. CREWTHER, B., J. KEOGH, J. CRONINI \& Ch. COOK, 2006. Possible Stimuli for Strength and Power Adaptation. In: Sports Med. 36:215.

3. GOTSHALK, L. A., C. C. LOEBEL, B. C., NINDL et al., 1997. Hormonal responses of multiset versus single-set heavy-resistance exercise protocols. In: Can J Appl Physiol. 22(3):244-55.

4. GRANDYS, M., J. MAJERCZAK, J. KULPA, K. DUDA, U. RYCHLIK \& J. A. ZOLADZ, 2016. The importance of the training-induced decrease in basal cortisol concentration in the improvement in muscular performance in humans. In: Physiol Res. 65(1):109-20. 
5. GUILHEM, G. C., N. HANON, D. GENDREAU. BONNEAU, A. GUÉVEL J.A. \& M. CHENNAOUI, 2015. Salivary Hormones Response to Preparation and Pre-competitive Training of World-class Level Athletes. In: Front Physiol. 16(6):333. HAFF, G.G.,

6. JACKSON, J. R., N. KAWAMORI et al., 2008. Force-time curve characteristics and hormonal alterations during an eleven-week training period in elite women weightlifters. In: J Strength Cond Res. 22(2):433-46.

7. HÄKKINEN, K. \& A. PAKARINEN, 1991. Serum hormones in male strength athletes during intensive short term strength training. In: Eur J Appl Physiol Occup Physiol. 63(34):194-9.

8. HÄKKINEN K. \& A. PAKARINEN, 1993. Acute hormonal responses to two different fatiguing heavy-resistance protocols in male athletes. In: $J$ Appl Physiol. 74(2):882-7.

9. HÄKKINEN, K., A. PAKARINEN, M. ALÉN, H. KAUHANEN \& P. V. KOMI, 1987. Relationships between training volume, physical performance capacity, and serum hormone concentrations during prolonged training in elite weight lifters. In: Int $J$ Sports Med. 8(1):61-5.

10. HÄKKINEN, K., A. PAKARINEN, M. ALÉN, H. KAUHANEN \& P. V. KOMI, 1988. Neuromuscular and hormonal adaptations in athletes to strength training in two years. In: J Appl Physiol. 65(6):2406-12.

11. HOFFMAN, J. R., 2014. Physiological Aspects of Sports Training and Performance. Human Kinetics. 9781450442244.

12. HUG, M., P. E. MULLIS, M. VOGT, N. VENTURA \& H. HOPPELER, 2003. Training modalities: over-reaching and over-training in athletes, including a study of the role of hormones. In: Best Pract Res Clin Endocrinol Metab. 17(2):191-209. Review.

13. JOHNSON, S. G., G. F.JOPLIN \& J. M. BURRIN, 1987. Direct assay for testosterone in saliva: relashionship with a direct serum free testosterone assay. In: Clinica Chimica Acta. 163:309; 318.

14. KIRSCHBAUM, C. \& D. H.HELLHAMMER,1989. Salivary cortisol in psychobiological research: an overview. In: Neuropsychobiology. 22:150-69.

15. KRAEMER, R. R., J. L. KILGORE, G. R. KRAEMER \& V. D. CASTRACANE, 1992. Growth hormone, IGF-I, and testosterone responses to resistive exercise. In: Med Sci Sports Exerc. 24(12):1346-52.

16. KRAEMER, W. J., 1997. A serie of studies - the physiological basis for strength training in American football: fact over philosophy. In: Journal of Strength and Conditioning Research, 11(3), 131-142. 
17. KRAEMER, W. J., D. N. FRENCH, N. J. PAXTON et al., 2004. Changes in exercise performance and hormonal concentrations over a big ten soccer season in starters and nonstarters. In: J Strength Cond Res. 18(1):121-8.

18. KRAEMER, W. J., \& N. A. RATAMESS, 2005. Hormonal responses and adaptations to resistance exercise and training. In: Sports Med. 35(4):339-61. Review.

19. KRAEMER, W. J., J. S. VOLEK, J. A. BUSH, M. PUTUKIAN \& W. J. SEBASTIANELLI, 1998. Hormonal responses to consecutive days of heavy-resistance exercise with or without nutritional supplementation. In: J Appl Physiol. 85(4):1544-55.

20. KREHER, J. B. \& J. B. SCHWARTZ, 2012. Overtraining syndrome: a practical guide. In: Sports Health. 4(2):128-38.

21. LAC, G., N. LAC \& A. ROBERT, 1993. Steroid assays in saliva: A method to detect plasmatic contaminations. In: Arch. Int. Physiol. Bioch. Biophys. 101: 257-262.

22. LACZO, E., G. BUZGÓ \& M. KOVÁČ, 2012. Ukazovatele intenzity zat'aženia pri komplexných tréningových prostriedkoch vo vzpieraní. In: Vzpieranie I. ICM Agency: Bratislava. 2012. ISBN 978-80-89257-56-0

23. LUISI, M. \& F. FRANCHI, 1984. Salivary steroid measurement. An alternative approach to plasma assays in assessing endocrine function. In: Front Oral Physiol. 5: 124-154.

24. MCGUIGAN, M. R., A. D. EGAN \& C. FOSTER, 2004. Salivary Cortisol Responses and Perceived Exertion during High Intensity and Low Intensity Bouts of Resistance Exercise. In: J Sports Sci Med. 3(1):8-15.

25. MORGAN, K. A., 2009. Salivary testosterone and cortisol measurments in professional elite rugby union players. Treforest. Thesis for the degree of Master of Philosophy. University of Glamorgan.

26. PASSELERGUE, P. \& G. LAC, 1999. Saliva cortisol, testosterone and T/C ratio variations during a wrestling competition and during the post-competitive recovery period. In: Int. J. Sports Med. 20(2):109-13.

27. POTTEIGER, J. A., L. W. JUDGE, J. A. CERNY \& V. M. POTTEIGER, 1995. Effects of Altering Training Volume and Intensity on Body Mass, Performance, and Hormonal Concentrations in Weight-Event Athletes. In: Journal of Strength \& Conditioning Research.9(1).

28. SPIERING, B. A., W. J. KRAEMER, J. M. ANDERSON et al. 2008. Effects of elevated circulating hormones on resistance exercise-induced Akt signaling. In: Med Sci Sports Exerc. 40(6):1039-48. 
29. STOREY, A. \& H. K. SMITH, 2012.Unique aspects of competitive weightlifting: performance, training and physiology. In: Sports Med. 42(9):769-90. Review.

30. TREMBLAY, M.S., J. L. COPELAND \& W. VAN HELDER, 2004. Effect of training status and exercise mode on endogenous steroid hormones in men. In: J. Appl. Physiol. 96(2):531-9.

31. VERVOORN, C., A. M. QUIST, L. J. VERMULST, W. B. ERICH, W. R. DE VRIES \& J. H. THIJSSEN, 1991. The behaviour of the plasma free testosterone/cortisol ratio during a season of elite rowing training. In: Int. J. Sports Med. 12(3):257-63.

32. VINING, R. F., R. A. MCGINLEY, J. J. MAKSYVITIS, \& K. Y. HO, 1983. Salivary cortisol: a better measure of adrenal cortical function than serum cortisol. In: Ann Clin Biochem. 20:329-35.

33. VIRU, A., VIRU, M., 2004. Cortisol--essential adaptation hormone in exercise. In: Int $J$ Sports Med. 25(6):461-4. Review.

34. WANG, C., S. Plymate, E. NIESChlaG \& C. A. PAUlSEN, 1981. Salivary testosterone in men: further evidence of a direct correlation with free serum testosterone. In: J Clin Endocrinol Metab. 53(5):1021-4. 